\title{
A Review on Enhancement of Refrigeration Effect of Vortex Tube
}

\author{
Ankita Adana ${ }^{+*}$ and P.M.Khanwalkar ${ }^{\dagger}$ \\ †Mechanical Engineering Department, SCOE, Vadgaon, Savitribai Phule Pune University, Pune, Maharashtra, India \\ Accepted 03 March 2016, Available online 15 March 2016, Special Issue-4 (March 2016)
}

\begin{abstract}
The technology is proliferating and making our environment unwell for existence, by emission of hazardous elements that causes depletion of ozone layer and affect the human comfort. The objective of the dissertation is to study the concept of vortex tube that can be used for refrigeration purpose and in future can be the best replacement over conventional refrigeration systems. This paper reviews the research to enhance the refrigeration effect by changing nozzle geometry, changing the geometry of the cylindrical tube in to conical tube at various cone angles, installing a diffuser between the vortex tube outlet and hot valve and the reason of energy separation within the vortex tube.
\end{abstract}

Keyword: Refrigeration Effect, Vortex tube etc.

\section{Introduction}

Vortex tube is a simple device consists of no moving parts and was first described by Ranque (1933) and examined experimentally by Hilsch (1942) hence the name Ranque Hilsch. The main components of the vortex tube are nozzle, diaphragm, chamber, cylindrical tube, cone valve, hot air outlet, cold air outlet; sometimes diffuser is also installed between the cylindrical tube outlet and the hot valve. The main working principle depends upon the pressure difference that causes the separation of air stream. When the compressed air is injected tangentially in to the chamber through the nozzle, the swirls more like a tornado is formed due to the pressure difference that causes the separation of compressed air in to two air streams i.e. hot air stream and cold air stream. Because of lower density of the hot air it gets accumulated at the peripheral of the inner tube, while the cold air is present in the middle of the tube. The hot air is sent back to the atmosphere from the hot air outlet present at the right hand side of the vortex tube, whereas the cold air exits from the opposite side of the hot air outlet.

Many researches had been carried out to find the reason of separation of air streams happening inside the tube. Mischer and Bespalov explained that energy separation takes place because of entropy generation, still the theory is unacceptable. Kassener and knoernschild in their work proposed that the pressure difference causes the separation of air streams also they have undergone the work that converts initially free vortex in to forced vortex, since then vortex tube

*Corresponding author: Ankita Adana has become a topic of research. Changes in the components of vortex tube has practiced and analyzed the results with the Ranque-Hilsch tube. A diffuser was installed between the cone valve and the vortex tube outlet, experiments shows that the cold air temperature TC reduced tremendously and increases the refrigeration effect. The cylindrical tube geometry when converted to conical tube, the hot air temperature $\mathrm{TH}$, and cold air temperature $\mathrm{TC}$ were quite high compared to conical tube. The results obtained were impressive by changing the aspect ratio (L/D), number of nozzles.

Vortex tube has many advantages it is a simple device, no moving parts, no electricity or chemicals, small and light weight, low cost, less maintenance, instant cold air, durable because of material used (stainless steel, aluminum), clean work media. Vortex tube has following applications it is used in spaced suits, for spot cooling in welding, in CCTV camera. In future because of its advantages vortex tube can be the best replacement over conventional refrigeration system.

\section{Literature Review}

0. M. Kshirsagar1, et al. in the paper Effect of Geometric Modifications on the Performance of Vortex Tube - A Review explained the working principle of vortex tube. A detailed description of the parts of vortex tube has been highlighted. Literature review of this paper is to understand the effect of various parameters like inlet pressure of air, number of nozzles, cold orifice diameter and hot end valve angle on the performance of vortex tube. Also by the literature review it is clear that there is no theory so 
perfect, which gives the satisfactory explanation of the vortex tube phenomenon.

$\mathrm{N}$. Li, et al. in the paper Experimental study of the energy separation in a vortex tube reveals certain factors that influence the compressed air to split in to two air streams i.e. hot and cold air streams respectively. A detailed study has been carried out to understand the reason of the splitting of air stream. The experimental results show that the static temperature in the center of vortex tube is higher than that of the peripheral part.

Y.T. $W u$, et al. in the paper Modification and experimental research on vortex tube has done certain modifications in the parameter of the vortex tube to investigate the changes in the efficiency of the tube. The literature review of this paper is to modify the nozzle and a diffuser is also installed to mark the changes affecting the refrigeration effect.

C. H. Marquesa, et al. in the paper Construction design of a vortex tube for several inlet stagnation pressures the paper deals with the numerical models used to analyse the geometrical optimization of the vortex tube. Turbulence models like KE model and RANS model are briefly described. The main purpose of the work is to increase the amount of energy obtained at cold end.

S.Rejin, H.Thilakan in the paper Experimental Analysis on Vortex Tube Refrigerator Using Different Conical Valve Angles, this paper describes the experimental study on vortex tube refrigerator with different conical valve angle at the hot side and the effect of cold orifice diameter at cold side on the performance of vortex tube refrigerator. The experiment was started from the design and fabrication stage of a vortex tube refrigerator. Compressed air at pressure of 5bar was introduced at the inlet. For this given inlet conditions a maximum temperature reduction of $7^{\circ} \mathrm{C}$ was achieved. This result attained for an operating condition of $10^{\circ}$ conical valve angle and cold orifice diameter of $6 \mathrm{~mm}$.

A.V. Khait, et al. in the paper Semi-empirical turbulence model for numerical simulation of swirled compressible flows observed in RanqueeHilsch vortex tube this paper presents a three-dimensional numerical model of swirled compressible flow in the RanqueeHilsch vortex tube. The modification of the energy conservation equation used in Reynolds Averaged Naviere Stokes (RANS) numerical simulations. While the additional turbulent heat transfer mechanism caused by gas compressibility is taken into account in the proposed equation, it is not applied in standard RANS models. The data were obtained both by standard and proposed energy conservation equations using the $\mathrm{k}-\varepsilon$ turbulence model. The application of the proposed energy conservation equation was shown to increase the accuracy of static and total temperature distribution prediction. The objective of this paper is the demonstration of the applicability of the new numerical model based on the proposed energy conservation equation after the calibration of empirical coefficients.

Muhammad Mohiuddin in the conference paper A Fresh Look at Vortex Tubes Used as Expansion Device in Vapor Compression Systems explains that the overall expansion process in a vortex tube therefore approaches isentropic rather than isenthalpic expansion, and the internal flow separation is achieved without any moving parts, resulting in robust and inexpensive designs. Commercially available vortex tubes are almost exclusively used for spot cooling in industrial applications and use compressed air as the working fluid. In addition, vortex tubes have been gaining lots of attention in air-conditioning and refrigeration research, because of the possibility to replace the expansion valve of vapor compression systems with this low-cost device that can recover expansion work that would otherwise be lost in the isenthalpic throttling process. Most of the work on vortex tubes used for refrigeration has been on numerical studies, and many of them predict very optimistic energy efficiency improvements.

R.Madhu Kumar, et al.,in the paper Performance Improvement of Ranque-Hilsch Vortex Tube by Using Conical Hot Tube In this paper, vortex tube with cylindrical and conical hot tubes performance is compared. It was found that the vortex tube with a conical angle of about $2.5^{\circ}$ surpassed the cylinder tube by $25 \% \sim 30 \%$ in COP. The conical vortex tube reaches the same or more performance than the normal tube but with a smaller length.

Nader Pormahmoud, et al. in the paper The Effect of L/D Ratio on the Temperature Separation in the Counterflow Vortex Tube includes the aspect ratio of the vortex tube. The selection criteria of the design parameters have been well explained.

Mahesh Kumar Dhanghar, et al. in the paper, Designing Aspects of a Vortex Tube Cooling System, analyze the performance of counter flow vortex tube by changing the various geometrical parameters such as length and diameter of hot end pipe and also changing the nozzle number of the orifice to increase the COP of the vortex tube.

\section{Schematic of Vortex Tube}

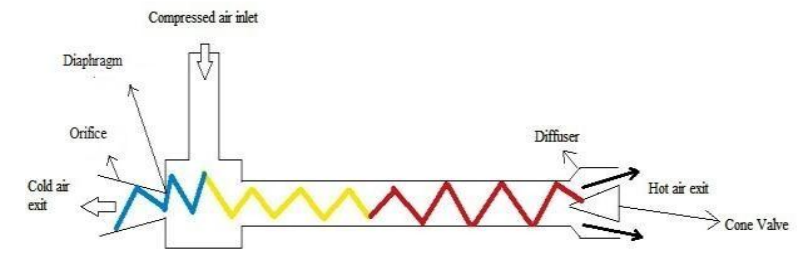

Fig.3.1 Vortex Tube with Diffuser

The above figure shows the outlet of the vortex tube sometimes by installing a diffuser between the vortex outlet and cone valve improves the COP of the system by decreasing the temperature difference at the cold 
end. Diffuser provides the expansion to the discharge at the hot end by increasing the pressure as a result of which the cold air temperature further decreases providing good refrigeration effect.

\section{The layout of a Vortex Tube}

It consists of the following parts:

1) Nozzle: A nozzle is a device designed to control the direction or characteristics of a fluid flow (especially to increase velocity) as it exists (or enters) an enclosed chamber or pipe.

2) Diaphragm: A diaphragm is a sheet of a semi flexible material anchored at its periphery and most often round in shape. It serves either as a barrier between two chambers, moving slightly up into one chamber down into the other depending on the differences in pressure, or as a device that vibrates when certain frequency are applied to it.

3) Valve: A device used for controlling the flow of fluid in the pipe or other enclosure. Control is by means of a movable element that opens, shuts, or partially obstructs an opening in passage way.

4) Hot air side: Hot side is cylindrical in cross section and is of different length as per design.

5) Cold air side: Cold side is cylindrical portion through which cold air is passed.

6) Chamber: Chamber is portion of nozzle and facilities the tangential entry of high velocity air stream into hot side. Generally the chambers noncircular form, but they are gradually converted into spiral form.

7) Diffuser: Diffuser is the device that allows the high velocity air to expand and lowers the temperature as well as pressure of the air. By the installation of a diffuser it affects the temperature of cold air.

\section{Experimental Setup}

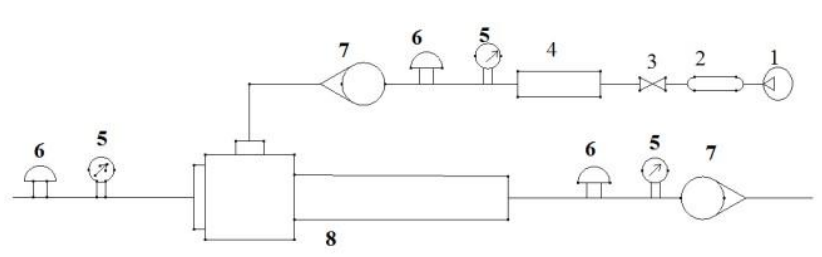

Fig.4.1 Layout of Experimental Setup

The required instruments are selected as per the capacity, measuring range accuracy and availability in the market.

\section{Thermodynamic Parameters of Vortex Tube}

The cold flow mass ratio is the most important parameter used for indicating the vortex tube performance. The cold mass fraction is the ratio of mass of cold air that is released through the cold end of the tube to the total mass of the input compressed air. It is represented as follows: $\varepsilon=\frac{\mathrm{m}_{\mathrm{e}}}{\mathrm{m}_{\mathrm{t}}}$

Where, mc represents the mass flow rate of the cold stream released, mi represents the inlet or total mass flow rate of the pressurized air at the inlet. Therefore $\mathrm{E}$ varies in the range of $0-1$.

Cold air temperature difference or temperature reduction is defined as the difference between inlet flow temperature and cold air temperature:

\begin{tabular}{|c|c|c|c|}
\hline $\begin{array}{l}\text { Sr. } \\
\text { No. }\end{array}$ & Particulars & Range & Quantity \\
\hline 1. & $\begin{array}{c}\text { Compressor } \\
\text { (Two Stage } \\
\text { Reciprocating) }\end{array}$ & 6 to 8 bars & 1 \\
\hline 2. & Tank & - & 1 \\
\hline 3. & Valve & - & 1 \\
\hline 4. & FRL Unit & 8 bars & 1 \\
\hline 5. & $\begin{array}{c}\text { Pressure } \\
\text { Gauge }\end{array}$ & 10 bars & 3 \\
\hline 6. & $\begin{array}{c}\text { Temperature } \\
\text { Indicator }\end{array}$ & $\begin{array}{l}-50^{\circ} \mathrm{C}- \\
200^{\circ} \mathrm{C}\end{array}$ & 3 \\
\hline 7. & Rotameter & $\begin{array}{l}0-100 \mathrm{LPH} \\
0-200 \mathrm{LPH}\end{array}$ & 2 \\
\hline 8. & Vortex Tube & - & - \\
\hline
\end{tabular}

Fig.4.1 List of required instruments

$\Delta \mathrm{Tc}=\mathrm{Ti}-\mathrm{Tc}$

Where $\mathrm{Ti}$ is the inlet flow temperature and $\mathrm{Tc}$ is the cold air temperature. Similarly, hot air temperature difference is defined as:

$\Delta \mathrm{Th}=\mathrm{Th}-\mathrm{Ti}$

The refrigerating / cooling effect produced by the cold air of vortex tube is given as:

$\mathrm{Qc}=\mathrm{mc} \operatorname{cp}(\mathrm{Ti}-\mathrm{Tc})$

Since cooling and heating streams are obtained simultaneously the heating effect produced by the vortex tube is given as:

$\mathrm{Qh}=\mathrm{mh} \operatorname{cp}(\mathrm{Th}-\mathrm{Ti})$

The coefficient of performance (COP) is normally defined as the cooling power Qc gained by the system divided by the work power $P$ input. So the COP can be expressed as:

$$
\operatorname{COP}_{\text {ref }}=\frac{\gamma \varepsilon}{\gamma-1} \frac{\left(\mathrm{T}_{\mathrm{i}}-\mathrm{T}_{\mathrm{c}}\right)}{\mathrm{T}_{\mathrm{i}} \ln \left(\frac{\mathrm{p}_{\mathrm{i}}}{\mathrm{p}_{\mathrm{a}}}\right)}
$$


Here the cooling power can be calculated according to the cooling capacity of the cold exhaust gas. The Carnot COP is the maximum efficiency for all the heat engines.

The COPs for Carnot cycles are:

$$
\operatorname{COP}_{\text {heat pump }}=\frac{\gamma(1-\varepsilon)}{\gamma-1} \frac{\left(\mathrm{T}_{\mathrm{h}}-\mathrm{T}_{\mathrm{i}}\right)}{\mathrm{T}_{\mathrm{i}} \ln \left(\frac{\mathrm{p}_{\mathrm{i}}}{\mathrm{p}_{\mathrm{a}}}\right)}
$$

\section{Comparison of Cylindrical Vortex Tube Vs Conical Vortex Tube}

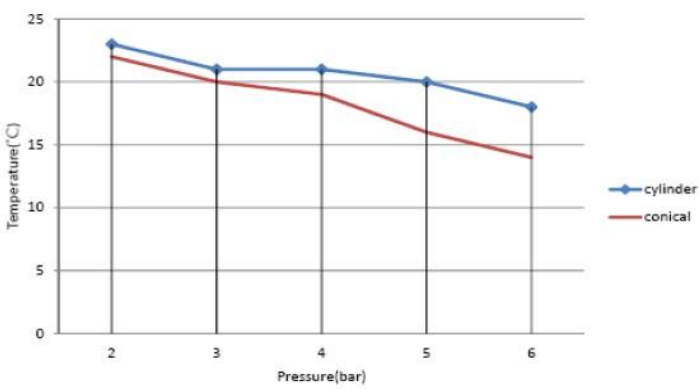

Fig.6.1 Graph showing Inlet Pressure Vs Cols Air Temperature

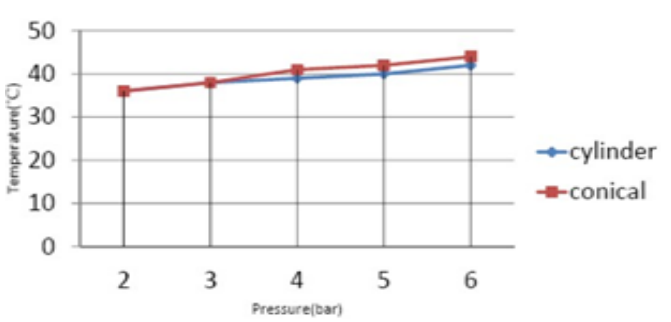

Fig.6.2 Graph showing Inlet Pressure Vs Hot Air Temperature

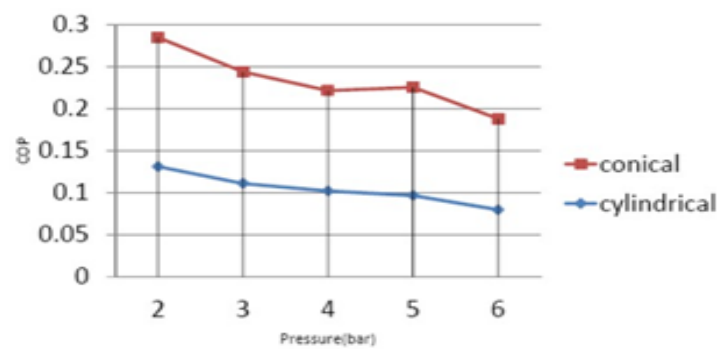

Fig.6.3 Graph showing Inlet Pressure Vs COP

The above figures shows the graph plotted between Inlet Pressure Vs Cold Air Temperature, Inlet Pressure Vs Hot Air Temperature and Inlet Pressure Vs COP, from above results it is clear that COP obtained in case of conical tube is $25 \%$ to $30 \%$ higher than that obtained in case of cylindrical tube at pressure 2 to 4 bars. Also the experiment shows that the hot air temperature increases and cold air temperature decreases in case of conical tube when compared to cylindrical tube. Hence in order to improve the refrigeration effect we may change the geometry of cylindrical vortex tube to conical vortex tube. Below are the tables showing the readings of conical tube and cylindrical tube.

Table.6.1 Readings with Cylindrical Vortex Tube

\begin{tabular}{|c|c|c|c|c|}
\hline S:NO & $\begin{array}{c}\text { Pressure } \\
\mathbf{P i}(\mathbf{b a r})\end{array}$ & $\begin{array}{c}\text { Cold } \\
\text { temperat ure } \\
\mathbf{T}_{\mathbf{c}}\left({ }^{\circ} \mathbf{C}\right)\end{array}$ & $\begin{array}{c}\text { Hot } \\
\text { temperature } \\
\mathbf{T}_{\mathbf{h}}\left({ }^{\circ} \mathbf{C}\right)\end{array}$ & COP \\
\hline $\mathbf{1}$ & 2 & 23 & 36 & 0.0798 \\
\hline $\mathbf{2}$ & 3 & 21 & 38 & 0.0967 \\
\hline $\mathbf{3}$ & 4 & 21 & 39 & 0.1022 \\
\hline $\mathbf{4}$ & 5 & 20 & 40 & 0.1111 \\
\hline $\mathbf{5}$ & 6 & 18 & 42 & 0.1311 \\
\hline
\end{tabular}

Table.6.2 Readings with Conical Vortex Tube

\begin{tabular}{|c|c|c|c|c|}
\hline S:NO & $\begin{array}{c}\text { Pressure } \\
\mathbf{P i ( b a r )}\end{array}$ & $\begin{array}{c}\text { Cold } \\
\text { temperature } \\
\mathbf{T} \mathbf{c}\left({ }^{\circ} \mathbf{C}\right)\end{array}$ & $\begin{array}{c}\text { Hot } \\
\text { temperature } \\
\mathbf{T h}\left({ }^{\circ} \mathbf{C}\right)\end{array}$ & COP \\
\hline $\mathbf{1}$ & 2 & 22 & 36 & 0.1085 \\
\hline $\mathbf{2}$ & 3 & 20 & 38 & 0.1289 \\
\hline $\mathbf{3}$ & 4 & 19 & 41 & 0.1196 \\
\hline $\mathbf{4}$ & 5 & 16 & 42 & 0.1330 \\
\hline $\mathbf{5}$ & 6 & 14 & 44 & 0.1540 \\
\hline
\end{tabular}

Table.6.3 Readings of COP with both Cylindrical and Conical Vortex Tub

\begin{tabular}{|c|c|c|c|c|}
\hline S.No & $\begin{array}{c}\text { Pressure } \\
\text { in } \\
\text { bar }\end{array}$ & $\begin{array}{c}\text { COP of } \\
\text { cylinder } \\
\text { hot tube }\end{array}$ & $\begin{array}{c}\text { COP of } \\
\text { conical } \\
\text { hot tube }\end{array}$ & $\begin{array}{c}\text { \% increase } \\
\text { in COP of } \\
\text { conical } \\
\text { hot tube }\end{array}$ \\
\hline $\mathbf{1}$ & 2 & 0.0798 & 0.1085 & 35.96 \\
\hline $\mathbf{2}$ & 3 & 0.0967 & 0.1289 & 33.29 \\
\hline $\mathbf{3}$ & 4 & 0.1022 & 0.1196 & 17.25 \\
\hline $\mathbf{4}$ & 5 & 0.1111 & 0.1330 & 19.71 \\
\hline $\mathbf{5}$ & 6 & 0.1311 & 0.1540 & 17.46 \\
\hline
\end{tabular}

\section{Effects on the Performance of Vortex Tube by Spiral Nozzle}

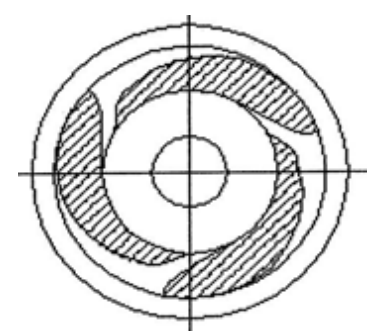

Fig.7.1 Spiral Nozzle

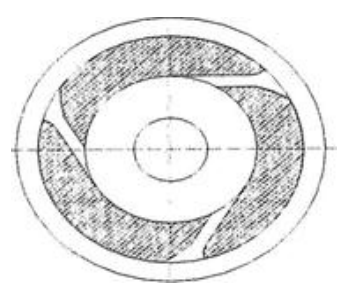

Fig.7.2 Nozzle of normal rectangle 


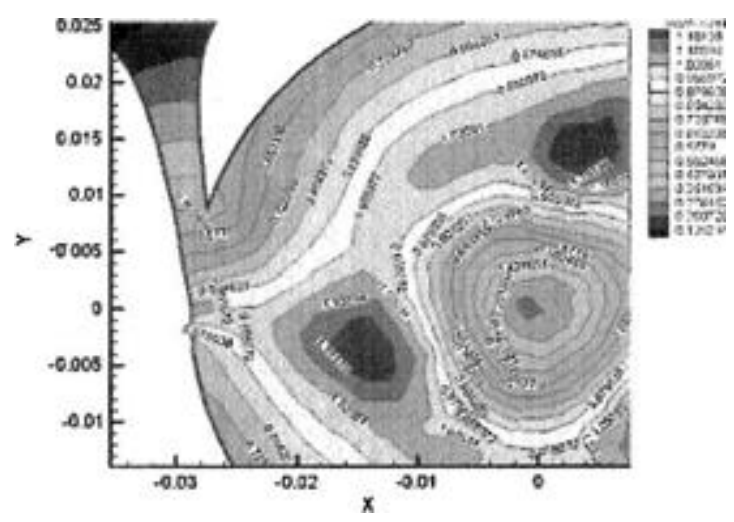

Fig.7.3 Nozzles proposed by authors

It is important to have a high peripheral velocity in the portion of the tube immediately after the nozzle. The nozzle curve affects the performance of vortex tube. The two conventional types of nozzles are normal rectangle and Archimedes' spiral nozzles which are shown in the above figures. Experiments were done with these types of nozzles, respectively, at the same condition that the inlet pressure is $0.4 \mathrm{MPa}$ (absolute) and inlet temperature is $24^{\circ} \mathrm{C}$, the results were shown in fig 7.4. We can see from the curve that the cooling effect of different nozzles varied with the change of $c$ and that the improved nozzle had better cooling effect than other normal nozzles. Similarly, the heating effect of vortex tube with the improved nozzle is better than that of conventional vortex tube slightly, shown in fig 7.5 .

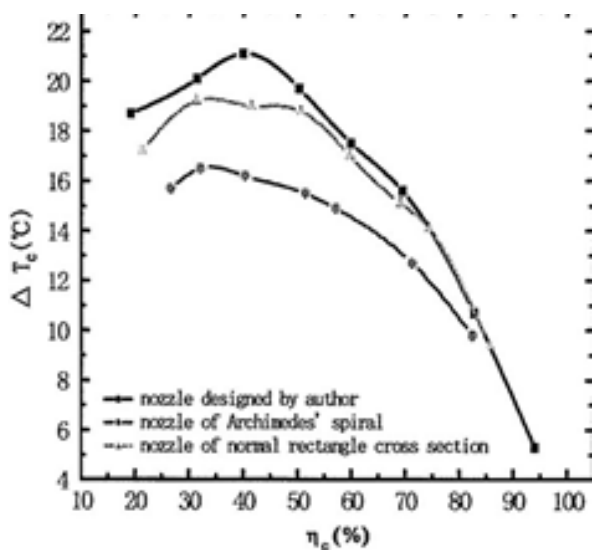

Fig.7.4 Effect of various nozzles on cooling effects

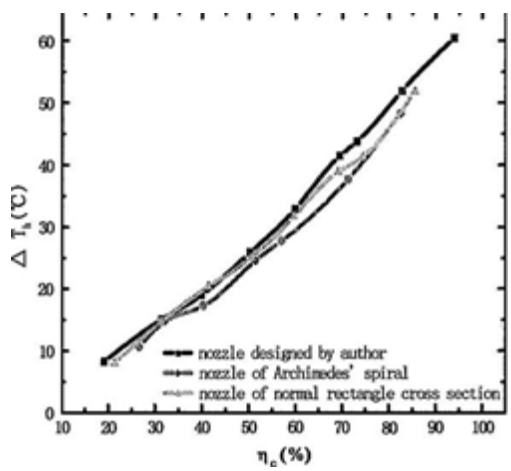

Fig.7.5 Effect of various nozzles on heating effects

\section{Effect on the performance of Vortex Tube by diffuser}
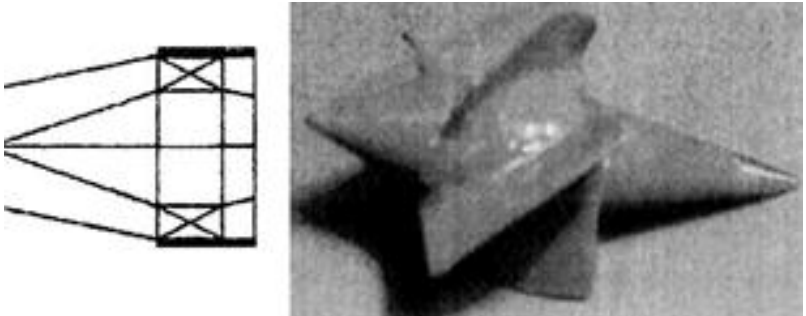

Fig.8.1 Picture of the diffuser

A contrast experiment between vortex tubes with and without diffuser was carried out, and the results were shown in fig. 8.2, 8.3 where an exciting advancement can been seen easily that the cooling effect of the former is lower by $50 \mathrm{C}$ in maximum than that of latter, and the heating effect becomes a little better too.

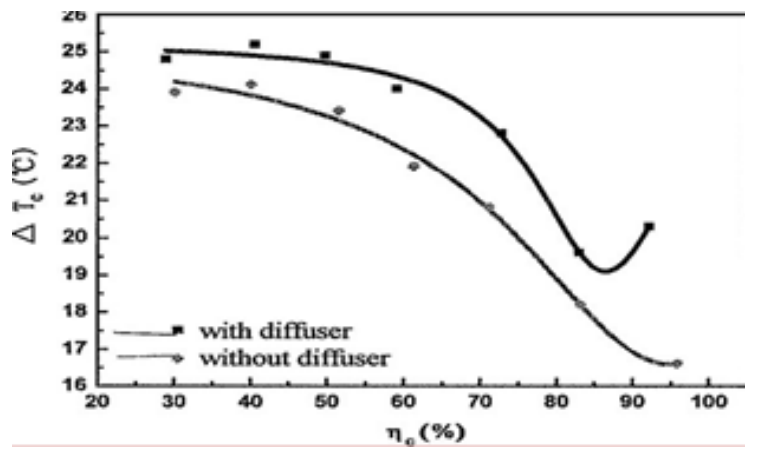

Fig.8.2 Effect of the diffuser on cooling effects

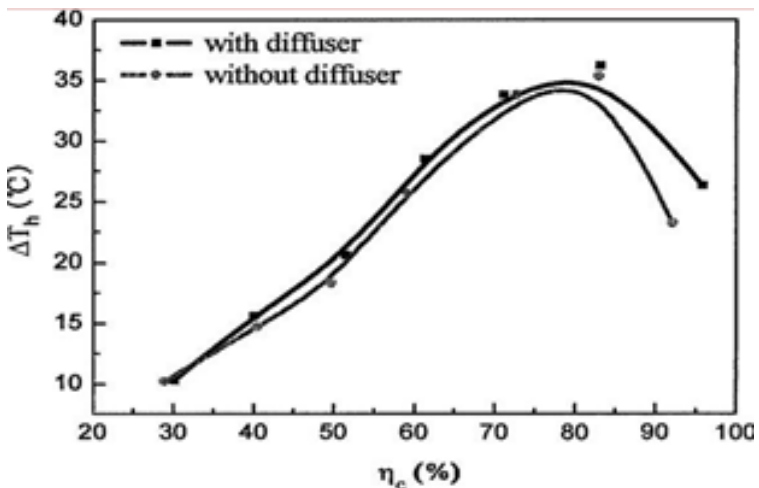

Fig.8.3 Effect of the diffuser on heating effect

\section{Conclusion}

Vortex tube is a simple device consists of no moving parts. Presence of diffuser results in better refrigeration effect and decreases the cold temperature abruptly, by changing the geometry of cylindrical tube to conical tube shows better results by vast temperature change at cold and hot end. The results have been shown by using tables and graphs; presently 
the topic is still under research to enhance the refrigeration effect obtained by vortex tube. It has many applications and is discussed in the paper. Due to advantages of vortex tube it can be the best replacement over conventional refrigeration in future that is environment friendly.

\section{Acknowledgements}

I am thankful to my guide Prof. P.M.Khanwalkar forhis guidance and being source of motivation to complete the work. I would like to thank Prof. V.N. Kapatkar, (Co- ordinator Heat Power Engineering) for his help \& cooperation provided for the seminar work. I am thankful to Prof. (Dr.) Y. P. Reddy, Vice-Principal and Head of Mechanical Engineering Department, SinhgadCollege of Engineering, for his cordial support. I also thank Prof. (Dr.) S. D. Lokhande, Principal, Sinhgad College of Engineering, for giving me this opportunity to present this review paper an integralpart of M.E (Mechanical) Heat Power Engineering course.

\section{References}

Kshirsagar O. M., Ankolekar V. V, Kapatkar V. N., Effect of Geometric Modifications on the Performance of Vortex Tube - A Review, Int. Journal of Engineering Research and Applications, Vol. 4, Issue 11(Version 3), November 2014 pp.92-98.

Li N., Zeng Z.Y., Wang Z , Han X.H., Chen G.M., Experimental study of the energy separation in a vortex tube, International Journal of Refrigeration 55(2015). Department of Mechanical Engineering, University College London, Torrington Place, London, WC1E 7JE, UK.
Wu Y.T.,Ding Y.,Ji Y.B.,Ma C.F.,Ge M.C., Modification and experimental research on vortex tube, International Journal of Refrigeration 30 (2007). Institute of Engineering Thermophysics, Chinese Academy of Science, Beijing, China.

Marquesa C.H., Isoldia L.A., Santos E.D.. Rocha L.A., Constructal Design of a Vortex Tube for Several Inlet Stagnation Pressures, Universidade Federal do Rio Grande FURG, Escola de Engenharia.

Rejin S, Thilakan H., Experimental Analysis on Vortex Tube Refrigerator Using Different Conical Valve Angles, International Journal of Engineering Research and Development, Volume 3, Issue 4 (August 2012), PP. 33-39, Dept.of Mechanical Engineering, TKM College of Engineering, India.

Khait A.V, Noskov A.S, Lovtsov A.V, Alekhin V.N., Semiempirical turbulence model for numerical simulation of swirled compressible flows observed in RanqueeHilsch vortex tube, Ural Federal University named after the first President of Russia B.N.Yeltsin

Mira St., Ekaterinburg 620002, Russia. S.C.o.E, M.E (Mechanical) (Heat Power Engineering) (2015-2016)

Muhammad Mohiuddin, Stefan Elbel, A Fresh Look At Vortex Tubes Used As Expansion Device In Vapor Compression Systems, International Refrigeration and Air Conditioning Conference. Paper 1393.

Madhu R. Kumar, Nageswar V. Reddy, Dinesh B. Babu, Performance Improvement of Ranque-Hilsch Vortex Tube by Using Conical Hot Tube, International Journal of Engineering Research ISSN:2319-6890)(online) 2347-5013 (print) Volume No.3 Issue No: Special 1, pp: 48-51

Nader Pourmahmoud, Abdol Reza Bramo, The Effect of L/B Ratio on the Temperature Separation in the Counterflow Vortex Tube, IJRRAS, Volume 6, issue 1, January -2011.

Mahesh Kumar Dhangar, manujendra Sharma, Mangu Singh Chouhan, Designing Aspects of a Vortex Tube Cooling System, Proceedings of IRF International Conference. 22nd March-2015, Jaipur India. 